\title{
PROGRAM STUDI PERBANDINGAN MAZHAB DAN PROBLEMATIKA SEPI PEMINAT
}

\author{
Oleh: \\ Drs. Abd. Mukhsin, M.Soc.Sc. \\ abdmukhsin@uinsu.ac.id \\ Dr. Ramadhan Syahmedi Siregar, M.Ag. \\ ramedi1975@gmail.com \\ Keduanya adalah Dosen pada Fakultas Syari'ah \& Hukum \\ UIN Sumatera Utara
}

\begin{abstract}
Abstrak
Program Studi Perbandingan Mazhab atau Prodi PM adalah satu dari enam program studi yang ada di Fakultas Syari'ah dan Hukum UIN Sumatera Utara saat ini dan juga merupakan salah satu dari dua program studi yang memiliki akreditasi A disamping Program Studi Mu`amalah (Hukum Ekonomi Islam). Namun beberapa tahun belakangan, peminat atau calon mahasiswa prodi ini sangat minim. Penelitian ini bertujuan untuk mengetahui faktor penyebab sepinya peminat calon mahasiswa dan faktor-faktor apa saja yang paling dominan yang melatarbelakangi sepinya peminat program studi Perbandingan Mazhab ini. Penelitian ini adalah penelitian kualitatif dan informan datanya selain bersumber dari guru dan siswa/i dua sekolah tingkat Aliyah (SLTA) yang ada di Kota Medan, juga diperoleh dari mahasiswa baru Prodi PM dan dosen Fakultas Syari'ah UIN Sumatera Utara. Temuan penelitian menunjukkan bahwa cita-cita siswa/i kelas XII atau calon mahasiswa, informasi yang lengkap tentang suatu program studi, dan keterbatasan lowongan kerja lulusan atau alumni merupakan faktor-faktor dominan yang membuat rendahnya minat siswa/i Aliyah / SLTA mendaftar di Program Studi Perbandingan Mazhab. Kedepan, prodi perlu melakukan sosialisasi yang lebih intens dan harus tepat sasaran, menjalin kerjasama yang lebih serius dengan berbagai pihak, memberi stimulus kepada calon mahasiswa dengan menyediakan beasiswa bidikmisi atau beasiswa dan bantuan lainnya, melakukan alumni tracing (penelusuran alumni) dan mengoptimalkan peran website fakultas dan alumni.
\end{abstract}

Kata kunci: problematika, Perbandingan Mazhab, sepi, dan peminat.

\section{A. Pendahuluan}

Pada hakikatnya pendidikan adalah upaya sadar dari suatu masyarakat dan pemerintah suatu negara untuk menjamin kelangsungan hidup dan kehidupan generasi penerus, selaku warga masyarakat, bangsa dan negara, secara berguna dan bermakna serta mampu mengantisipasi hari depan mereka yang senantiasa berubah dan selalu terkait dengan konteks dinamika budaya, bangsa, negara, dan hubungan internasionalnya. Kemampuan warga negara suatu negara, untuk hidup berguna dan 
bermakna serta mampu mengantisipasi perkembangan, perubahan masa depannya, memerlukan pembekalan ilmu pengetahuan, teknologi dan seni (iptek) yang berdasarkan nilai-nilai keagamaan dan nilai-nilai budaya bangsa. Nilai-nilai dasar tersebut menjadi panduan dan mewarnai keyakinan serta menjadi pegangan hidup warga negara dalam kehidupan bermasyarakat, berbangsa dan bernegara.

Pendidikan merupakan pilar tegaknya bangsa. Melalui pendidikanlah bangsa akan tegak mampu menjaga martabat. Dalam UU 20/2003 tentang Sistem Pendidikan Nasional, Pasal 3, disebutkan "Pendidikan Nasional berfungsi mengembangkan kemampuan dan membentuk watak serta peradaban bangsa dan bermartabat dalam rangka mencerdaskan kehidupan bangsa, bertujuan untuk mengembangkan potensi peserta didik agar menjadi manusia yang beriman dan bertaqwa kepada Tuhan Yang Maha Esa, berakhlak mulia, sehat, berilmu, cakap, kreatif, mandiri, dan menjadi warga negara yang demokratis serta bertanggung jawab. ${ }^{1}$

Perkembangan dunia yang sangat pesat belakangan ini menuntut setiap institusi yang memberikan pelayanan kepada masyarakat untuk secara terus menerus meningkatkan mutu pelayanannya. Jika hal ini gagal dilakukan maka hampir pasti bahwa institusi tersebut akan mengalami kegagalan dalam misinya, atau setidaknya akan tertinggal jauh dari pesaing-pesaingnya.

Dalam kaitan semacam itulah terasa mendesak untuk melaksanakan kegiatan peningkatan program studi yang memberikan kajian dan pengajaran bidang studi keagamaan pada mahasiswa. Salah satu bentuk peningkatan prodi adalah dengan mengembangkan dan mewujudkan visi misi yang telah ada.

Memilih program studi dalam suatu Perguruan Tinggi (PT) merupakan hal yang sangat signifikan dan menjadi penentu untuk mencapai cita-cita yang ingin diraih oleh seseorang. Program studi yang lebih menarik dan lebih diminati oleh calon mahasiswa biasanya program studi yang mempunyai visi misi yang jelas dan lebih terarah pada tujuan, yang mampu menjawab segala tantangan dan dapat menjadikan mahasiswa dan alumninya mampu bersaing secara ketat di dunia kerja.

Salah satu program studi yang ada di Fakultas Syari`ah adalah Prodi Perbandingan Mazhab (PM) ${ }^{2}$ di samping Prodi Ahwalus Syakhsiyah (Hukum Keluarga Islam), Prodi Jinayah (Pidana Islam), Siyasah (Hukum Tata Negara Islam), dan Mu`amalah (Hukum Ekonomi Islam) ${ }^{3}$. Semua Prodi yang ada di fakultas syari ah jika dilihat dari segi pemaknaan dan penerjemahan Prodi - Prodi yang ada secara umum sangat menarik dan mempunyai daya tarik tersendiri.

Namun yang paling memprihatinkan dari semua Prodi yang ada di Fakultas Syari ah adalah prodi Perbandingan Mazhab (PM), di mana peminat ${ }^{4}$ calon mahasiswa

\footnotetext{
${ }^{1}$ http://tunas63.wordpress.com/2008/11/07/ visi-misi-tujuan-pendidikan-nasional.

${ }^{2}$ Jurusan Perbandingan Mazhab mempunyai kompetensi menguasai perban-dingan mazhab serta mampu menyelesaikan berbagai perkara dan kasus hukum yang ada. Lihat Buku Panduan Akademik IAIN-SU 2008/2009, h. 52-53.

3 Nur Ahmad Fadhil Lubis, Studi Islam, Tp, tt., h. 207.

${ }^{4}$ Minat adalah suatu rasa lebih suka dan rasa ketertarikan pada suatu hal atau aktivitas, tanpa ada yang menyuruh. Minat pada dasarnya adalah penerimaan akan suatu hubungan antara diri sendiri dengan sesuatu di luar diri. Semakin kuat atau dekat hubungan tersebut, semakin besar minat. Lihat Slameto, Belajar dan Faktor-Faktor yang Mempengaruhinya, (Jakarta: Rineka Cipta, 1980), h. 180 Lihat juga, Tim Penyusun Kamus Pusat Bahasa, Kamus Besar Bahasa Indonesia, Edisi Ketiga, Departeman Pendidikan dan Kebudayaan, (Jakarta: Balai Pustaka, 2001).
} 
untuk memasuki prodi tersebut sangat sedikit atau bisa diistilahkan dengan prodi langka peminat. Hal ini sangat memprihatinkan, karena jika dilihat dari segi kurikulumnya prodi ini sangat relevan dengan kajian-kajian keislaman. Selian itu, jika dibandingkan dengan prodi lain, prodi PM mempunyai potensi lebih unggul, dari segi keilmuan, karena prodi membahas beberapa mazhab yang ada. Dengan demikian ilmunya lebih mendalam dibanding prodi lain, sebab prodi lain tidak sampai pada perbandingan antara satu mazhab dengan mazhab lainnya. Demikian juga dengan dosen-dosen yang ada di prodi PM umumnya terdiri dari dosen senior dan mempunyai pengalaman yang cukup dalam dunia pendidikan dan pengajaran.

Dengan adanya masalah yang dijelaskan di atas, maka peneliti ingin meneliti lebih lanjut tentang Program Studi Perbandingan Mazhab yang sepi peminat calon mahasiswa untuk memasuki prodi tersebut dengan judul: Program Studi Perbadingan Mazhab dan Problematika Sepi Peminat.

\section{Rumusan Masalah}

Melihat dari latar belakang masalah di atas, yakni sepinya peminat calon mahasiswa untuk mendaftarkan diri ke program studi Perbandingan Mazhab, maka permasalahan pokok dalam penelitian ini dapat dirumuskan sebagai berikut:

a. Apakah yang menyebabkan sepinya peminat calon mahasiswa UIN-SU untuk mendaftarkan diri ke program studi Perbandingan Mazhab?

b. Apa faktor-faktor yang paling dominan yang melatarbelakangi sepinya peminat Program studi Perbandingan Mazhab?

\section{Metode Penelitian}

a. Jenis penelitian

Jenis penelitian ini adalah penelitian kualitatif. Penelitian kualitatif sering disebut dengan penelitian naturalistik. etnografik, studi kasus atau fenomenologi. Penelitian kualitatif menghasilkan data deskriptif berupa katakata yang dapat diamati. Data kualitatif adalah data yang berbentuk kata-kata, bukan dalam bentuk angka. ${ }^{5}$

Sementara permasalahan yang diteliti adalah mengulas tentang faktor yang mempengaruhi sepinya peminat calon mahasiswa untuk memasuki prodi perbandingan mazhab di Fakultas Syari ah dan Hukum UIN-SU Medan.

Sedangkan pendekatan yang digunakan adalah pendekatan antropologis dan sosiologis (socio approach) yakni pendekatan kenyataan kondisi masyarakat dengan mempelajari fenomena sosial calon mahasiswa baru yang ingin mendaftarkan diri ke Prodi Perbandingan Mazhab UIN Sumatera Utara Medan.

b. Lokasi penelitian

Penelitian dilaksanakan di Fakultas Syari ah dan Hukum UIN Sumatera Utara dan informan datanya selain bersumber dari guru dan siswa/i dua sekolah tingkat Aliyah (SLTA) yang ada di Kota Medan, juga diperoleh dari mahasiswa baru Prodi Perbandingan Mazhab dan dosen Fakultas Syari'ah UIN Sumatera Utara.

c. Alat pengumpulan data yang digunakan adalah:

1) Kuesioner (angket), yang diberikan kepada 34 orang guru MAN 1 Medan dan 26 orang guru Raudhatul Hasanah. Angket juga diberikan kepada 19

\footnotetext{
${ }^{5}$ Depdiknas, Pengolahan dan Analisis Data Penelitian (Jakarta: Depdiknas, 2008), h. 34.
} 
orang mahasiswa baru Prodi Perbandingan Mazhab dan 20 orang siswa/i Madrasah Aliyah Laboratorium UIN Sumatera Utara. Siswa/i Madrasah Aliyah Laboratorium UIN Sumatera Utara berasal dari jurusan agama, IPS dan IPA.

2) Interview (wawancara) yang dilakukan terhadap lima orang guru MAN 1 Medan, dua orang guru Raudhatul Hasanah Medan dan tiga orang dosen Fakultas Syari'ah dan Hukum UIN SU.

3) Focus Group Discussion (FGD). FGD menghadirkan satu orang narasumber, yaitu Dr. Mhd. Syahnan, MA dari Lembaga Penjaminan Mutu UIN Sumatera Utara, seorang moderator, yaitu sdr. Andi Suhendra, S.Pd.I. dari guru Madrasah Aliyah Laboratorium UIN Sumatera Utara dan 20 orang siswa/i Madrasah Aliyah Laboratorium UIN Sumatera Utara.

d. Analisis data

Analisis yang dilakukan dapat dikemukakan sebagai brikut: pemilihan dan pengklasifikasian/pengelompokan data, menginformasikan pemilihan dan kelompok data secara rinci kemudian menarik kesimpulan berdasarkan pertanyaan-pertanyaan/permasalahan penelitian yang telah diajukan. Proses ini secara ringkas melalui tahapan-tahapan berdasarkan teknik analisis data yang dikembangkan oleh Miles dan Huberman yang melalui tiga level: reduksi data, display data dan penarikan kesimpulan. ${ }^{6}$

\section{B. Pembahasan}

\section{Faktor-Faktor yang Menyebabkan Sepinya Peminat Prodi Perbandingan Mazhab}

\section{a. Informasi yang diperoleh dari guru melalui wawancara}

Ketika ditanyakan kepada Guru MAN 1 tentang Prodi Perbandingan Mazhab, hanya beberapa orang guru yang dianggap mengetahui prodi tersebut dari lebih kurang 20 (dua puluh orang) guru yang hadir saat itu di ruang guru. Akhirnya, hanya lima orang guru saja yang bersedia diwawancarai, sebagian di wawancarai di hari yang sama dan sebagian lagi diwawancarai pada hari yang lain. Dari interview tersebut diperoleh informasi bahwa:

1) Sosialisasi Prodi Perbandingan Mazhab kepada siswa di sekolah tersebut sangat kurang atau sangat minim. Bahkan salah seorang guru mengatakan bahwa sejak tahun 1992 menurut beliau, sosialisasi prodi ini secara khusus tidak pernah dilakukan. ${ }^{7}$

2) Guru selalu menyarankan siswa memilih prodi dengan meneliti dan memastikan bahwa prodi yang dipilih terakreditasi, namun demikian siswa MAN yang tertarik kuliah di UIN Sumatera Utara yang masuk Fakultas Syari'ah dan Hukum lebih cenderung memilih prodi selain Prodi Perbandingan Mazhab. ${ }^{8}$ Mereka tidak mendaftar di prodi tersebut karena syarat (tuntutan) kemampuan bahasanya, terutama kemampuan bahasa Arab, lebih tinggi dibandingkan dengan syarat (tuntutan) kemampuan bahasa yang diperlukan oleh prodi lain.

\footnotetext{
${ }^{6}$ M.B Miles and A.M. Huberman, Qualitative Data Analysis: An Expanded Sourcebook, (Canada: Sage Publications, Thousand Oaks, 1994), h. 21-22.

7 Wawancara dengan ibu Nur Khadrah, S.Pd. di MAN 1 Medan pada hari Jum'at, tanggal 31 Agustus 2018 dari jam 10.30 - 11.15 Wib.

8 Wawancara dengan guru MAN 1 Medan, bapak Humala Harahap dan bapak Amir Husein pada hari Jum'at, tanggal 24 Agustus 2018 jam $09.00-10.30$.
} 
3) Lowongan kerja output prodi ini perlu dipikirkan ulang. Artinya lowongan kerja alumni harus lebih diperluas. UIN Sumatera Utara dan secara khusus fakultas dan prodi perlu menjalin kerjasama dengan berbagai pihak atau dengan lembagalembaga lain yang berkompeten yang mungkin dapat menyediakan lapangan kerja bagi lulusannya. ${ }^{9}$

Sedangkan jawaban guru Raudhatul Hasanah dalam wawancara yang dilakukan di kantor guru dan kepala sekolah tentang keberadaan Prodi Perbandingan Mazhab di Fakultas Syari'ah dan Hukum UIN SU adalah seperti rangkuman di bawah ini:

1) Sosialisasi secara langsung mengenai Prodi Perbandingan Mazhab oleh tim UIN SU ke siswa/i Aliyah di Yayasan Wakaf Raudhatul Hasanah tidak pernah dilakukan sehingga siswa/i kurang mengetahui informasi tentang prodi tersebut. Harapan mereka di masa yang akan datang informasi yang ada tentang prodi PM baik dalam bentuk leaflet, brosur maupun informasi lewat internet supaya lebih cepat disampaikan agar siswa/i mengetahui informasi yang lengkap tentang prodi dimaksud.

2) Di masa lalu banyak alumni Raudhatul Hasanah yang masuk ke IAIN atau UIN SU, ada beberapa yang memilih prodi Perbandingan Mazhab. Namun akhir-akhir ini, siswa/i yang menamatkan sekolahnya dari Raudhatul Hasanah lebih banyak yang kuliah ke Jawa, kalaupun ada yang masuk ke UIN SU, mereka lebih banyak memilih prodi Bahasa Inggris dan matematika. Sudah menjadi trend diantara siswa/i Raudhatul Hasanah dikunjungi oleh kakak-kakak kelas mereka yang kuliah di Jawa, sang kakak kelas berbagi cerita dengan adik-adik kelasnya dan selanjutnya membuat adik-adik kelas mereka terobsesi untuk kuliah ke Jawa pula, dan umumnya siswa/i tersebut memilih fakultas-fakultas umum. ${ }^{10}$

\section{b. Informasi yang diperoleh dari sebahagian dosen Fakultas Syari'ah dan Hukum melalui wawancara}

Pencarian informasi juga dilakukan dengan mewawancarai tiga orang dosen Fakultas Syari'ah dan Hukum.

Dari wawancara yang dilaksanakan dengan dosen tersebut diperoleh informasi dan pendapat bahwa:

1) Jika dilihat dari segi silabus prodi, sebetulnya silabusnya sudah bagus. Akan tetapi kadang-kadang input atau calon mahasiswa yang akan diterima sering terlupakan padahal keberhasilan prodi sangat tergantung kepada input yang ada. Fakultas dan prodi mestinya pro aktif mendatangi dan mengundang siswa/i pesantren-pesantren untuk masuk ke prodi Perbandingan Mazhab dan memberi mereka prioritas beasiswa. Dari mana beasiswanya diambil tentu pihak yang berwenang di kampus UIN SU lebih tahu soal itu. ${ }^{11}$

2) Prodi Perbandingan Mazhab ini memang prodi yang ditakuti mahasiswa karena materi kuliahnya banyak yang berbahasa Arab. Di masa lalu (era 1985 an) ada sebahagian mahasiswa yang meminta dipindahkan dari prodi tersebut setelah ditentukan oleh fakultas, berdasarkan nilai akademik, masuk di prodi Perbandingan Mazhab. Padahal ketika ada penerimaan calon hakim, dari 11 orang yang lulus dari

\footnotetext{
9 Wawancara dengan bapak Muhammad Jamil dan ibu Rosmaida Siregar, guru MAN 1 Medan, pada hari Jum'at 31 Agustus 2018 jam 09.00 - 10.30 Wib.

10 Wawancara dengan bapak Mukhlis Ihsan dan bapak Supriadi, keduanya guru Raudhatul Hasanah Medan,pada hari Ahad, 2 September 2018, jam 10.00-12.00 Wib di kompleks sekolah tersebut.

11 Wawancara dengan Dr. Zulkarnain Nasution, MA pada tanggal 7 September 2018 di ruang Dosen, Fakultas Syari'ah UIN SU, jam 08.30 - 09.30 Wib.
} 
satu kelas kuliah dalam satu kali penerimaan cpns, 9 orang adalah alumni prodi Perbandingan Mazhab. ${ }^{12}$

3) Pembukaan prodi baru di UIN SU dapat juga menjadi penyebab minimnya peminat prodi Perbandingan Mazhab, jika yang diharapkan alumni SMA dan SMK. Jadi, UIN SU dan Fakultas Syari'ah dan Hukum perlu memberi perhatian khusus kepada prodi-prodi yang dianggap peminatnya sedikit, dengan memberikan kemudahan kepada calon-calon mahasiswa dari siswa/i madrasah dan pesantren. Kemudahannya adalah dengan memberi calon-calon mahasiswa tersebut beasiswa, baik dari beasiswa bidikmisi maupun dari yang lainnya. ${ }^{13}$

\section{c. Informasi yang diperoleh dari Focus Group Discussion}

Setelah mewancarai sebagian guru di MAN 1 Medan dan beberapa guru Raudhatul Hasanah, kemudian menyebarkan angket kepada mereka dan kepada mahasiswa baru Program Studi Perbandingan Mazhab dan mewawancarai sebagian dosen Fakultas Syari'ah dan Hukum, dilanjutkan dengan Focus Group Discussion (FGD). ${ }^{14}$ Focus Group Discussion dilaksanakan dengan mengundang 1 orang narasumber yang dianggap berkompeten di bidangnya dan mengetahui tentang Program Studi Perbandingan Mazhab, yakni Dr. Mhd. Syahnan, MA dari Lembaga Penjaminan Mutu UIN Sumatera Utara dengan moderator sdr. Andi Suhendra, S.Pd.I. dan 20 orang siswa/siswi Madrasah Aliyah Laboratorium UIN SU, yang berasal dari beberapa jurusan seperti yang tertera di tabel 1 berikut:

Tabel 1

Peserta Focus Group Discussion (FGD) untuk Mengetahui Penyebab \& Faktor Paling Dominan Yang Menyebabkan Sepinya Peminat Prodi Perbandingan Mazhab (PM)

\begin{tabular}{|l|l|l|}
\hline Jurusan & No. & \multicolumn{1}{|c|}{ Nama } \\
\hline Agama & 1. & Latifah Kusuma Dewi \\
\cline { 2 - 3 } & 2. & Zukhrina Azzukhruf \\
\cline { 2 - 3 } & 3. & Muhammad Risky \\
\cline { 2 - 3 } & 4. & Ray Albani Pulungan \\
\cline { 2 - 3 } & 5. & Muhammad Hafiz Asri \\
\cline { 2 - 3 } & 6. & Hotmartua \\
\hline IPS 1 & 1. & Alan Nirwan \\
\cline { 2 - 3 } & 2. & Rizki Apriansyah \\
\cline { 2 - 3 } & 3. & Nur Syadina Putri \\
\cline { 2 - 3 } & 4. & Mifta Khoiriah \\
\cline { 2 - 3 } & 5. & Indah Wulandari \\
\hline IPS 2 & 1. & Yuda Pratama \\
\hline
\end{tabular}

${ }^{12}$ Wawancara dengan Dr. Pangeran Harahap, MA pada tanggal 10 September 2018 di ruang Dosen, Fakultas Syari'ah UIN SU, jam 09.30 - 10.30 Wib.

13 Wawancara dengan ibu Dra. Armauli Rangkuti, MA pada tanggal 14 September 2018 di ruang Dosen, Fakultas Syari'ah UIN SU, jam 11.00 - 12.00 Wib.

${ }^{14}$ Focus Group Discussion dilaksanakan pada hari Sabtu 29 September 2018 dari pukul 08.30 s/d 12.30 Wib bertempat di Aceh Corner, MMTC Jl. Slamet Ktaren Pasar V Medan Estate, dengan narasumber Dr. Mhd. Syahnan,MA dan moderator sdr. Andi Suhendra, S.Pd.I. ditambah dengan 20 (dua puluh orang) siswa Madrasah Aliyah Laboratorium UIN SU, peneliti, pembantu peneliti dan panitia FGD. 


\begin{tabular}{|l|l|l|}
\hline \multirow{5}{*}{} & 2. & Mhd. Bayu Agistia \\
\cline { 2 - 3 } & 3. & Muhammad Khadafi \\
\cline { 2 - 3 } & & \\
\cline { 2 - 3 } & 4. & Zulhamdi Siregar \\
\hline IPA & 1. & Muhammad Bimbim Arby \\
\cline { 2 - 3 } & 2. & M. Sifa Rizaka \\
\cline { 2 - 3 } & 3. & Fitka Istikhomah \\
\cline { 2 - 3 } & 4. & Dea Ananda \\
\cline { 2 - 3 } & 5. & Dewi Triyana \\
\hline Jumlah & 20 & orang siswa / $i$ \\
\hline
\end{tabular}

Dari diskusi yang berjalan, informasi yang mencuat dalam diskusi dapat disimpulkan sebagai berikut:

1) Sosialisasi Prodi Perbandingan Mazhab sudah dilakukan, tetapi pertanyaan berikutnya, apakah sosialisasi yang telah dilakukan itu tepat sasaran? Kemana sosialisasi dilakukan perlu menjadi pertimbangan matang. Sasaran yang paling tepat antara lain adalah ke sekolah-sekolah yang merupakan kantong-kantong calon mahasiswa yang mumpuni dalam bahasa Arab disamping memiliki kemampuan yang baik dalam bahasa Inggris. Hal ini sangat penting karena setelah masuk kuliah, mahasiswa baru dituntut mampu membaca sumber-sumber bahan kuliah yang terdiri dari buku-buku konvensional dan kontemporer yang ditulis dalam kedua bahasa ini.

Dalam tahap ini, yang menjadi pokok perhatian adalah input calon mahasiswa prodi Perbandingan Mazhab. Kalau kemampuan bahasa Arab pun penting, ini berarti siswa lulusan SMA, SMK dan sekolah SLTA sejenis, bukan sasaran pertama sosialisasi dan tidak termasuk dalam objek prioritas yang diharapkan menjadi calon mahasiswa Prodi Perbandingan Mazhab.

Kalau input calon mahasiswanya lulusan pesantren, secara teori tentu output nya pun bakal lebih bagus dibandingkan dengan kalau inputnya dari lulusan SMA atau SMK. Kalaupun lulusan SMA dan SMK diterima juga, maka setelah kuliah berjalan, perlu dilakukan penyetaraan kemampuan keahlian ilmu alat (bahasa Arab) atau penyamaan gelombang di bidang bahasa dalam istilah siaran radio. Sebagai konsekwensinya, waktu kuliah akhirnya habis untuk penyetaraan kemampuan keahlian bahasa ini dan kematangan keilmuan Perbandingan Mazhabnya termarjinalkan.

Selanjutnya dalam sosialisasi, siswa perlu diberi stimulus dengan memaparkan prospek yang jelas lulusan prodi Perbandingan Mazhab, misalnya menjadi calon hakim, penasehat hukum (advokat), pegawai pencatat nikah dan (dalam pengumuman penerimaan CPNS tahun 2018) menjadi guru mata pelajaran Fiqh di lingkungan Kemenag.

2) Alumni tracing (penelusuran alumni) yang lebih serius dan lebih baik perlu dilakukan. Bank data alumni yang lebih lengkap dan informatif harus disiapkan. Data alumni yang tersedia selama ini sangat terbatas dan minim info. Banyak alumni yang sudah bekerja di tempat yang mapan tetapi tidak terexpose. Alumni yang sudah bekerja mestinya didata alamat, nomor handphone dan tempat kerjanya sehingga di saat diperlukan bantuannya, mudah merujuk alamat dan nomor HPnya.

3) Usaha menjemput bola harus dijalankan, apalagi setelah dibukanya beberapa fakultas umum di UIN Sumatera Utara. Siswa-siswi dari beberapa pesantren di Sumatera Utara, yang prestasinya bagus, diseleksi oleh universitas dan fakultas 
Syari'ah dan Hukum, yang terbaik dari mereka diberi prioritas untuk diterima di Prodi Perbandingan Mazhab. Untuk memberi stimulus kepada mereka, UIN Sumatera Utara mestinya menyiapkan beasiswa, apakah dananya diambil dari beasiswa bidikmisi maupun dari dana zakat yang dikelola Unit Pengumpul Zakat (UPZ) UIN Sumatera Utara. Hal ini sangat penting, karena kalau tidak demikian, dikhawatirkan peminat prodi Perbandingan Mazhab ke depan semakin menurun atau bahkan habis samasekali.

Selain informasi di atas, dari jawaban peserta diskusi terhadap pertanyaanpertanyaan yang ada di angket diketahui bahwa dari dua puluh siswa yang mengikuti Focus Group Discussion (FGD) hanya 3 (tiga) orang siswa atau $15 \%$ (lima belas persen) yang berminat masuk di Prodi Perbandingan Mazhab setelah mereka lulus dari sekolah madrasah yang mereka ikuti (Tabel nomor $2 \& 3$ ). Ketiga orang siswa tersebut berasal dari jurusan agama. Selebihnya, 17 (tujuh belas) siswa atau sama dengan $85 \%$ (delapan puluh lima persen) tidak berminat masuk Prodi Perbandingan Mazhab karena berbagai alasan. Dari yang 17 orang siswa tersebut, 3 (tiga) orang dari jurusan agama, 9 (sembilan) orang siswa dari jurusan IPS dan 5 (lima) orang siswa dari jurusan IPA. Singkatnya, sebagian besar yang tidak berminat dengan Prodi Perbandingan Mazhab tersebut berasal dari jurusan umum atau non agama.

Tabel 2

Persentase Siswa/i Berminat Atau Tidak Berminat Masuk Prodi Perbandingan Mazhab Fakultas Syariah UIN SU

\begin{tabular}{|c|l|c|c|}
\hline No & Nama & $\begin{array}{c}\text { Berminat ke Jurusan } \\
\text { Perbandingan Mazhab }\end{array}$ & \% \\
\hline 1 & Latifah Kusuma Dewi & Ya & $5 \%$ \\
\hline 2 & Zukhrina Az Zukhruf & Tidak & $5 \%$ \\
\hline 3 & M. Syafiq Ar Rizky & Ya & $5 \%$ \\
\hline 4 & Ray Albani Pulungan & Ya & $5 \%$ \\
\hline 5 & Muhammad Hafiz Asri & Ya & $5 \%$ \\
\hline 6 & Hotmartua Nasution & Tidak & $5 \%$ \\
\hline 7 & Alan Nirwan & Tidak & $5 \%$ \\
\hline 8 & Rizki Apriansyah & Tidak & $5 \%$ \\
\hline 9 & Nur Syahdina Putri & Tidak & $5 \%$ \\
\hline 10 & Miftah Khairiah & Tidak & $5 \%$ \\
\hline 11 & Indah Wulandari & Tidak & $5 \%$ \\
\hline 12 & Yuda Pratama & Tidak & $5 \%$ \\
\hline 13 & Mhd. Bayu Agistia & Tidak & $5 \%$ \\
\hline 14 & Muhammad Khadafi & Tidak & $5 \%$ \\
\hline 15 & Zulhamdi Siregar & Tidak & $5 \%$ \\
\hline 16 & Muhammad Bimbim Arby & Tidak & $5 \%$ \\
\hline 17 & Muhammad Sifa Pizaka Srg & Tidak & $5 \%$ \\
\hline 18 & Fitka Istikhomah & Tidak & $5 \%$ \\
\hline 19 & Dea Ananda Zetri & Tidak & $5 \%$ \\
\hline 20 & Dewi Triyana & & $\mathbf{1 0 0} \%$ \\
\hline & JUMLAH & & \\
\hline
\end{tabular}


Tabel 3

Kesimpulan Tabel Persentase Siswa/i Madrasah Aliyah Labolatorium UIN SU Yang Berminat Atau Tidak Berminat Masuk Prodi Perbandingan Mazhab Fakultas Syariah \& Hukum UIN SU

\begin{tabular}{|l|c|c|c|}
\hline No & Data Persentase & $\begin{array}{c}\text { Berminat ke } \\
\text { Jurusan } \\
\text { Perbandingan } \\
\text { Mazhab }\end{array}$ & $\begin{array}{c}\text { Tidak Berminat ke Jurusan } \\
\text { Perbandingan Mazhab }\end{array}$ \\
\hline & $\begin{array}{c}\text { Siswa/i Madrasah } \\
\text { Aliyah Labolatorium } \\
\text { UIN SU }\end{array}$ & $15 \%$ & $85 \%$ \\
\hline & Total & & $100 \%$ \\
\hline
\end{tabular}

Alasan siswa-siswi yang menjadi peserta diskusi meminati atau tidak meminati Prodi Perbandingan Mazhab bervariasi, demikian juga halnya dengan saran-saran mereka untuk perbaikan Prodi Perbandingan Mazhab (Tabel 4).

Tabel 4

Alasan \& Saran dari 20 Responden Siswa/i Berminat atau Tidak Berminat Masuk Prodi Perbandingan Mazhab Fakultas Syariah \& Hukum UIN SU

\begin{tabular}{|c|c|l|l|}
\hline No. & Berminat & \multicolumn{1}{|c|}{ Alasan } & \multicolumn{1}{|c|}{ Saran } \\
\hline 1 & Tidak & $\begin{array}{l}\text { kurang mendalami hukum- } \\
\text { hukum mengenai mazhab. }\end{array}$ & $\begin{array}{l}\text { Menyebarluaskan informasi } \\
\text { jurusan ini karena banyak dari } \\
\text { siswa/siswi yang tidak } \\
\text { mengenal jurusan } \\
\text { perbandingan mazhab ini. }\end{array}$ \\
\hline 2 & Tidak & tidak sesuai dengan cita-cita. & $\begin{array}{l}\text { seringlah untuk mengekpos } \\
\text { program studi perbandingan } \\
\text { mazhab. }\end{array}$ \\
\hline 3 & Tidak & $\begin{array}{l}\text { dikarenakan kurang memberi } \\
\text { gambaran yang nyata terhadap } \\
\text { peluang kerja, dan kurang } \\
\text { menonjol di masyarakat. }\end{array}$ & $\begin{array}{l}\text { studi perbandingan mazhab } \\
\text { ini membuat program } \\
\text { beasiswa keluar negeri. }\end{array}$ \\
\hline 4 & Ya & $\begin{array}{l}\text { dikarenakan membahas tentang } \\
\text { fatwa-fatwa ulama. }\end{array}$ & $\begin{array}{l}\text { lebih memperhatikan kondisi } \\
\text { dari peminat terhadap } \\
\text { perbandingan mazhab } \\
\text { tersebut. }\end{array}$ \\
\hline 5 & Ya & $\begin{array}{l}\text { Suka pembahasan dunia } \\
\text { perbandingan. }\end{array}$ & $\begin{array}{l}\text { Jurusan Perbandingan } \\
\text { Mazhab membuat metode }\end{array}$ \\
\hline
\end{tabular}




\begin{tabular}{|c|c|c|c|}
\hline & & & $\begin{array}{l}\text { menarik supaya mahasiswa } \\
\text { berminat dan tidak merasa } \\
\text { asing dengan jurusan } \\
\text { perbandingan mazhab. }\end{array}$ \\
\hline 6 & Ya & $\begin{array}{l}\text { dikarenakan mementingkan dan } \\
\text { mengutamakan kemaslahatan } \\
\text { umat Islam di akhir zaman, } \\
\text { mencintai perbedaan untuk } \\
\text { memajukan umat Islam serta } \\
\text { mengingat pentingnya untuk } \\
\text { memahami perbedaan-perbedaan } \\
\text { mengenai perbandingan mazhab } \\
\text { tersebut. }\end{array}$ & $\begin{array}{l}\text { lebih mengutamakan dan } \\
\text { memperhatikan mahasiswa/i } \\
\text { dalam meningkatkan setiap } \\
\text { aspek baik akademisi maupun } \\
\text { prestasi, serta menjadikan } \\
\text { mahasiswa/i perbandingan } \\
\text { mazhab ini sebagai panutan } \\
\text { dengan menonjolkan dan } \\
\text { memperdayakan ciri khas dari } \\
\text { jurusan perbandingan mazhab } \\
\text { itu sendiri. }\end{array}$ \\
\hline 7 & Tidak & $\begin{array}{l}\text { dikarenakan kurangnya fasilitas } \\
\text { yang ada dan kurangnya } \\
\text { pengembangan terhadap } \\
\text { perbandingan mazhab tersebut. }\end{array}$ & $\begin{array}{l}\text { harus bisa mengembangkan } \\
\text { program studi perbandingan } \\
\text { mazhab. }\end{array}$ \\
\hline 8 & Tidak & $\begin{array}{l}\text { dikarenakan ingin masuk di } \\
\text { jurusan hukum tata Negara yang } \\
\text { sesuai dengan cita cita karena } \\
\text { ingin menjadi pejabat. }\end{array}$ & $\begin{array}{l}\text { melakukan pengenalan } \\
\text { jurusan ini kepada siswa/i } \\
\text { sekolah-sekolah yang } \\
\text { memasuki gerbang } \\
\text { perkuliahan. }\end{array}$ \\
\hline
\end{tabular}

\begin{tabular}{|c|c|l|l|}
\hline No. & Berminat & \multicolumn{1}{|c|}{ Alasan } & \multicolumn{1}{|c|}{ Saran } \\
\hline 9 & Tidak & $\begin{array}{l}\text { tidak sesuai cita-cita dan tidak } \\
\text { tahu mengenai jurusan tersebut. }\end{array}$ & $\begin{array}{l}\text { mengenalkan ke semua orang } \\
\text { mengenai program studi } \\
\text { perbandingan mazhab. }\end{array}$ \\
\hline 10 & Tidak & $\begin{array}{l}\text { kurang mendalami apa } \\
\text { sebenarnya perbandingan } \\
\text { mazhab itu. }\end{array}$ & $\begin{array}{l}\text { sering mensosialisasikan } \\
\text { kepada masyarakat terutama } \\
\text { kepada siswa/siswi mengenai } \\
\text { perbandingan mazhab. }\end{array}$ \\
\hline 11 & Tidak & $\begin{array}{l}\text { dikarenakan cita-cita saudari } \\
\text { Indah berbeda dengan jurusan } \\
\text { tersebut, dan menurut saudari } \\
\text { tersebut program studi ini terlalu } \\
\text { ribet dan sulit. }\end{array}$ & $\begin{array}{l}\text { lebih banyak promosi serta } \\
\text { jangan lupa menjelaskan apa } \\
\text { itu perbandingan mazhab dan } \\
\text { lebih terbuka kepada publik } \\
\text { tentang program studi ini. }\end{array}$ \\
\hline 12 & Tidak & $\begin{array}{l}\text { dikarenakan kurang bisa } \\
\text { terealisasikan umumnya pada } \\
\text { dunia pekerjaan. }\end{array}$ & $\begin{array}{l}\text { lebih mensosialisasikan } \\
\text { program studi perbandingan } \\
\text { mazhab terutama dari segi } \\
\text { keunggulannya. }\end{array}$ \\
\hline
\end{tabular}




\begin{tabular}{|c|l|l|l|}
\hline 13 & Tidak & $\begin{array}{l}\text { dikarenakan jurusan } \\
\text { perbandingan mazhab ini tidak } \\
\text { memiliki daya tarik. }\end{array}$ & $\begin{array}{l}\text { perbandingan mazhab } \\
\text { memiliki daya tarik tersendiri } \\
\text { agar menambah minat untuk } \\
\text { jurusan ini. }\end{array}$ \\
\hline 14 & Tidak & $\begin{array}{l}\text { ketidaktertarikan terhadap } \\
\text { program studi tersebut } \\
\text { dikarenakan tidak tertarik } \\
\text { dengan pekerjaannya. }\end{array}$ & $\begin{array}{l}\text { perbanyak } \\
\text { mensosialisakannya. }\end{array}$ \\
\hline 15 & Tidak & $\begin{array}{l}\text { dikarenakan kurang suka untuk } \\
\text { memasuki program studi } \\
\text { tersebut. }\end{array}$ & $\begin{array}{l}\text { mempublikasikan jurusan } \\
\text { perbandigan mazhab tersebut } \\
\text { agar meningkatkan minat } \\
\text { terhadap program studi. }\end{array}$ \\
\hline 16 & Tidak & $\begin{array}{l}\text { tidak terlalu mendalami ilmu } \\
\text { agama tentang perbandingan } \\
\text { mazhab tersebut. }\end{array}$ & $\begin{array}{l}\text { perbanyaklah melakukan } \\
\text { pengenalan terhadap program } \\
\text { studi perbandingan mazhab. }\end{array}$ \\
\hline 17 & Tidak & $\begin{array}{l}\text { dikarenakan tidak banyak } \\
\text { lapangan pekerjaannya. }\end{array}$ & $\begin{array}{l}\text { buatlah program studi } \\
\text { perbandingan mazhab ini } \\
\text { terlihat lebih menarik agar } \\
\text { banyak peminatnya. }\end{array}$ \\
\hline 18 & Tidak & $\begin{array}{l}\text { kurangnya kejelasan dan peluang } \\
\text { kerja untuk kedepannya dan } \\
\text { kurang memahami mengenai } \\
\text { studi dari perbandingan mazhab } \\
\text { tersebut. }\end{array}$ & $\begin{array}{l}\text { seringlah mensosialisasikan } \\
\text { program studi Perbandingan } \\
\text { Mazhab kepada siswa/siswi. }\end{array}$ \\
\hline
\end{tabular}

\begin{tabular}{|r|c|l|l|}
\hline No. & Berminat & \multicolumn{1}{|c|}{ Alasan } & \multicolumn{1}{c|}{ Saran } \\
\hline 19 & Tidak & $\begin{array}{l}\text { kurang suka bidang yang } \\
\text { berbasis atau berhubungan } \\
\text { dengan hukum. }\end{array}$ & $\begin{array}{l}\text { agar siswa dan siswi lebih } \\
\text { peduli dengan politik dan } \\
\text { hukum Islam. }\end{array}$ \\
\hline 20 & Tidak & $\begin{array}{l}\text { kurangnya lapangan kerja bagi } \\
\text { lulusan proram studi } \\
\text { perbandingan mazhab tersebut. }\end{array}$ & $\begin{array}{l}\text { meningkatkan daya tarik agar } \\
\text { menimbulkan minat } \\
\text { siswa/siswi terhadap jurusan } \\
\text { perbandingan mazhab. }\end{array}$ \\
\hline
\end{tabular}

Dari tabel di atas dapat dilihat bahwa ada dua alasan pokok bagi siswa/i tertarik dengan Prodi Perbandingan Mazhab: 
Alasan pertama yang membuat mereka tertarik dengan prodi tersebut selain karena di prodi ini dipelajari berbagai fatwa ulama, di prodi yang sama, juga dibahas perbedaan pendapat ulama dan perbandingan hukum.

Alasan kedua yang membuat mereka tertarik dengan prodi Perbandingan Mazhab, terkait dengan hasil akhir yang bakal dicapai oleh mahasiswa setelah belajar di prodi PM, yang berarti bahwa mahasiswa yang lulus dari prodi diharapkan akan menjadi lebih dewasa dalam menyikapi perbedaan. Dengan bermodalkan sifat kedewasaan yang ada, diharapkan alumni tersebut dapat menunjukkan sifat-sifat kedewasaan diri yang dia miliki kepada masyarakat, di saat terjadi perbedaan hukum dalam kasus atau dalam peristiwa dan situasi tertentu. Jadi yang perlu dijaga adalah kemaslahatan umat Islam dalam konteks yang lebih luas.

\section{d. Informasi yang diperoleh dari guru melalui angket}

Informasi yang diperoleh dari guru MAN 1 Medan dan guru Raudhatul Hasanah melalui angket dapat dirangkum sebagai berikut:

Tingkat pengetahuan guru-guru di Raudhatul Hasanah terhadap prodi Perbandingan Mazhab lebih baik dan lebih mendalam dibandingkan dengan pengetahuan guru-guru MAN 1 Medan. Terbukti dari jumlah guru yang mengetahui prodi Perbandingan Mazhab lebih banyak dari jumlah guru di MAN 1, yaitu di Raudhatul Hasanah 30,8\% berbanding 20,5\%, sedangkan guru yang tidak mengetahui prodi Perbandingan Mazhab di Raudhatul Hasanah hanya 15,4\% dibanding 44,1\% di MAN 1 Medan.

Selanjutnya, sumber informasi tentang prodi Perbandingan Mazhab bagi guru di kedua sekolah tersebut didominasi oleh informasi melalui keluarga, sedangkan informasi dari tim sosialisasi UIN SU, berada pada posisi terendah sebagai pemberi informasi kepada mereka. Data ini memperkuat keterangan sebagian guru di MAN 1 dan di Raudhatul Hasanah bahwa tim sosialisasi UIN SU hamper tidak pernah hadir secara langsung di kedua sekolah tersebut.

Selain itu, dari hasil penelitian pada guru MAN 1 Medan dan Guru Raudhatul Hasanah Medan yang diperoleh melalui angket yang disebarkan kepada mereka, diketahui bahwa kebanyakan Guru MAN 1 Medan dan Guru Raudhatul Hasanah pernah menyarankan kepada siswa/i untuk masuk ke UIN SU dengan persentase angka sebesar 94\%. Dan ketika Guru MAN 1 Medan dan Guru Raudhatul Hasanah ditanyakan pernah atau tidak menyarankan siswanya untuk masuk ke Fakultas Syari'ah secara umum, maka jawabannya ialah pernah dengan angka sebesar 75\%. Namun demikian, walaupun saran tersebut telah sampai kepada siswa/i, terutama di Raudhatul Hasanah Medan, terbukti tidak banyak siswa yang tertarik secara nyata untuk kuliah di prodi Perbandingan Mazhab, terlihat dari minimnya siswa yang mendaftar ke prodi Perbandingan Mazhab tersebut.

\section{e. Informasi yang diperoleh dengan menggunakan angket dari mahasiswa baru dan siswa/i Madrasah Aliyah Laboratorium UIN SU}

Informasi penting lainnya adalah bahwa jumlah peminat prodi Perbandingan Mazhab secara global di lingkungan UIN SU lebih rendah dari jumlah peminat prodiprodi lain. Namun di dalam prodi Perbandingan Mazhab sendiri, dari mahasiswa baru T.A. 2018/2019 ada fenomena menarik yang menonjol, yaitu dari 21 orang mahasiswa baru, di dalam satu kelas yang masuk tahun ini, 11 orang (52\%) berasal dari SMA, 
disusul oleh tamatan Madrasah Aliyah 7 orang (33\%) dan hanya 2 orang (10\%) dari lulusan pesantren, sisanya 1 orang $(5 \%)$ adalah alumni dari SMK.

Informasi menarik lainnya yang berhasil dikumpulkan ketika ditanya tentang kemampuan mahasiswa baru membaca kitab kuning terkuak bahwa dari 20 orang mahasiswa baru, hanya 1 orang (5\%) yang mengaku mampu membaca kitab kuning, 14 orang $(70 \%)$ menyatakan tidak bisa, dan 5 orang $(25 \%)$ menjawab 'sedikit faham'. Informasi ini memberi makna bahwa $70 \%$ dari mereka tidak mempunyai dasar kemampuan membaca kitab kuning atau bahasa Arab yang baik ketika memasuki Prodi Perbandingan Mazhab.

Lebih lanjut, ketika ditanyakan cita-cita mahasiswa Prodi Perbandingan Mazhab setelah lulus, jawaban mereka menunjukkan bahwa sebagian besar (11 dari 14 orang) mahasiswa yang menjawab pertanyaan tersebut berkeinginan menjadi PNS, dari mereka 4 orang menjawab PNS secara umum dan sisanya 7 orang menyebut ingin menjadi PNS sebagai hakim. Hanya 3 orang dari 14 mahasiswa yang merespon pertanyaan tersebut dengan mengatakan setelah lulus nanti mereka berminat membuka lapangan kerja baru.

Siswa Madrasah Aliyah Laboratorium UIN Sumatera Utara yang lokasi sekolahnya berada di lingkungan UIN Sumatera Utara Jl. Pancing Medan Estate sendiri sangat minim pengetahuannya tentang Prodi Perbandingan Mazhab. Lalu yang menjadi pertanyaan kemudian, bagaimana pula dengan pengetahuan siswa sekolah lain yang lokasinya jauh dari UIN Sumatera Utara, tentu sudah pasti akan lebih minim pula. Karenanya, sosialisasi yang lebih serius dan lebih intens perlu dilanjutkan, tentu harus dilaksanakan dengan tepat sasaran pula.

Dari dua puluh siswa Madrasah Aliyah Laboratorium UIN SU yang mengikuti Focus Group Discussion (FGD) hanya 3 (tiga) orang siswa atau $15 \%$ (lima belas persen) yang berminat masuk di Prodi Perbandingan Mazhab setelah mereka lulus dari sekolah madrasah yang mereka ikuti. Ketiga orang siswa tersebut berasal dari jurusan agama. Selebihnya, 17 (tujuh belas) siswa atau 85\% (delapan puluh lima persen) tidak berminat masuk Prodi Perbandingan Mazhab. Dari yang 17 orang siswa tersebut, 3 (tiga) orang dari jurusan agama, 9 (sembilan) orang siswa dari jurusan IPS dan 5 (lima) orang siswa dari jurusan IPA. Singkatnya, sebagian besar yang tidak berminat dengan Prodi Perbandingan Mazhab tersebut berasal dari jurusan umum atau non agama.

Siswa/i yang tidak tertarik dengan Prodi Perbandingan Mazhab memberikan tiga alasan utama, yaitu:

Pertama, Program Studi Perbandingan Mazhab tersebut tidak sesuai dengan cita-cita mereka. jelas.

Kedua, peluang kerja alumni program studi tersebut, menurut siswa/i, kurang

Ketiga, kurang memadainya sarana dan fasilitas yang tersedia.

\section{Faktor-Faktor Dominan yang Menyebabkan Sepinya Peminat Prodi Perbandingan Mazhab}

Setelah dilakukan Focus Group Discussion dengan melibatkan secara langsung siswa/i Madrasah Aliyah Laboratorium UIN SU diketahui bahwa siswa/i Madrasah Aliyah Laboratorium UIN SU tidak tertarik dengan Prodi Perbandingan Mazhab karena tiga alasan utama yaitu:

1. Program Studi tersebut tidak sesuai dengan cita-cita siswa/i.

2. Tidak jelas / kurangnya peluang kerja lulusan (alumni) prodi tersebut.

3. Kurangnya fasilitas yang tersedia. 
Selanjutnya, saran yang mereka sampaikan untuk meningkatkan jumlah dan kuantitas peminat Prodi Perbandingan Mazhab adalah:

1. Prodi harus menyediakan beasiswa bagi alumninya untuk studi lanjutan ke luar negeri.

2. Ciri khas dari prodi dan alumninya harus lebih menonjol.

3. Sosialisasi Prodi Perbandingan Mazhab harus lebih diintensifkan.

4. Daya tarik Prodi Perbandingan Mazhab harus lebih ditingkatkan.

\section{Kesimpulan}

Data yang diperoleh dalam penelitian ini, baik data yang mendapatkannya melalui wawancara maupun dengan angket, menyediakan jawaban terhadap rumusan masalah penelitian tentang fakor-faktor yang menyebabkan sepinya peminat Prodi Perbandingan Mazhab, yang mencuat ke permukaan selama penelitian berlangsung adalah sebagai berikut:

1. Cita-cita seseorang. Diantara 20 orang informan yang terdiri dari siswa/i Madrasah Aliyah Laboratorium UIN SU hanya 3 orang yang berminat masuk ke Prodi Perbandingan Mazhab. Kebanyakan dari mereka menyatakan tidak tertarik dengan prodi tersebut karena tidak kepingin mempunyai karir di bidang hukum dan tidak kepingin menjadi hakim. Dari jawaban tersebut terlihat bahwa ada hubungan positif antara cita-cita seseorang dengan minatnya memilih program studi tertentu.

Lain halnya dengan keinginan dan cita-cita sebahagian besar mahasiswa baru Prodi Perbandingan Mazhab T.A. 2018/2019 yang berhasil lulus dan telah mengikuti perkuliahan, menjadi hakim bagi mereka merupakan profesi yang paling diidolakan setelah lulus dari Prodi Perbandingan Mazhab.

2. Ketersediaan informasi yang lengkap mengenai sebuah program studi. Minat siswa/i adakalanya dipengaruhi oleh informasi yang dia dapatkan melalui media surat kabar, eletronik dan media sosial. Minat siswa/i yang menjadi objek penelitian yang berhasil lulus memasuki prodi Perbandingan Mazhab, tergolong rendah walaupun fakultas dan prodi mengakui telah melakukan penyebaran informasi prodi Perbandingan Mazhab dengan baik.

3. Lowongan kerja yang sempit dan terbatas. Menurut sebahagian informan, lowongan kerja alumni Prodi Perbandingan Mazhab sangat terbatas. Pendapat ini muncul dari sebahagian guru dan siswa/i yang diteliti. Pendapat ini kemungkinan didasarkan pada kenyataan bahwa walaupun lulusan Prodi Perbandingan Mazhab memiliki kesempatan mendaftar pada beberapa lowongan kerja, namun dalam kenyataannya sangat sedikit yang dapat diterima menjadi pegawai atau karyawan.

Akhirnya, untuk meningkatkan jumlah peminat Prodi Perbandingan Mazhab di masa yang akan datang, Fakultas Syari'ah / Prodi Perbandingan Mazhab perlu melakukan / membuat:

1. Sosialisasi yang lebih intensif dan harus tepat sasaran.

2. Menjalin kerjasama yang lebih intens dengan berbagai pihak yang berkompeten untuk memastikan tersedianya lowongan kerja bagi alumni Prodi Perbandingan Mazhab di tempat / instansi partner bekerjasama.

3. Memberi stimulus kepada calon mahasiswa dengan cara jemput bola menyeleksi siswa/i dari pesantren-pesantren terbaik dan sekaligus men-switch sebagian beasiswa bidikmisi atau beasiswa dan bantuan lainnya kepada yang terpilih.

4. Alumni tracing (penelusuran alumni) dan pencatatan secara baik dalam buklet atau situs tertentu alamat, tempat kerja dan tempat dinas mereka sekaligus mencantukan 
photo masing-masing alumni di dalamnya. Catatan atau buklet dan situs tersebut dapat diakses dengan mudah oleh siapapun yang membutuhkan.

5. Mengoptimalkan peran website fakultas dan alumni prodi Perbandingan Mazhab sehingga informasi aktual mengenai lowongan kerja dan informasi penting lainnya bisa dengan cepat diketahui semua pihak yang berkepentingan.

\section{DAFTAR PUSTAKA}

Buku Panduan Akademik IAIN-SU 2008/2009.

Crown L dan A. Crow, Psikologi Belajar, Surabaya: Bina Ilmu, 1988.

Departemen Agama RI, Al-Qur`an dan Terjemah, CV. Diponegoro, Bandung, 2008.

Depdiknas, Pengolahan dan Analisis Data Penelitian, Jakarta: Depdiknas, 2008.

Direktorat Pembinaan Pendidikan dan Tenaga Kependidikan Direktorat Jenderal Pendidikan Menengah, Peminatan Peserta Didik SMA dan SMK, Jakarta: Kemendikbud, 2013.

Fakultas Syari'ah UIN Sumatera Utara, Borang Akreditasi Program Studi Perbandingan Mazhab 2015, Medan: Fakultas Syari'ah UIN Sumatera Utara, 2015).

Fuady, Munir, Teori-Teori dalam Sosiologi Hukum, Jakarta: Kencana, 2011.

Gunarsa, Singgih D., Psikologi Perawatan, Jakarta: BPK Gunung Mulia, 1989.

Ibrahim, Inovasi Pendidikan, Departemen Pendidikan dan Kebudayaan, Ditjen Dikti, 1988.

Juliandi, Azwar dan Irvan, Metode Penelitian Kualitatif, Bandung: Cita Pustaka Media, 2014.

Lubis, Nur Ahmad Fadhil, Studi Islam, Tp, tt.

M.B Miles and A.M. Huberman, Qualitative Data Analysis: An Expanded Sourcebook, Canada: Sage Publications, Thousand Oaks, 1994.

Manan, Mahmud (Ed),Tim Penyusun MKD IAIN Sunan Ampel, Studi Hukum Islam, Surabaya: IAIN Sunan Ampel Press, cet II, 2012.

Nazir, Moh, Metode Penelitian, Jakarta: Ghalia Indonesia.

Oemar Hamalik, Proses Belajar Mengajar, Bandung: Remaja Rosdakarya, 2009. 
P. Kleden, Ninuk, "Metodologi Pemahaman Bagi Penelitian Antropologi" dalam Jurnal Antropologi Indonesia, vol. 30 no. 2, 2006, Universitas Indonesia, Departemen Antropologi Fakultas Ilmu Sosial dan Ilmu Politik.

Sabri, Alisuf, Pengantar Psikologi Umum dan Perkembangan, Jakarta: Pedoman Ilmu Jaya, 1995.

Sardinan AM, Interaksi dan Motivasi Belajar Mengajar, Jakarta: Rarajawali, 1986.

Singer, Kurt, Membina Hasrat Belajar di Sekolah, Terj. Bergman Sitorus, Bandung: Remaja Rosdakarya, 1987.

Slameto, Belajar dan Faktor-Faktor yang Mempengaruhinya, Jakarta: Rineka Cipta, 1980.

Soetjipto, dan Kosasi, Raflis. Profesi Keguruan, Jakarta, Andi Mahasatya, 2004.

Syah, Muhibbin, Psikologi Pendidikan dengan Pendekatan Baru, Bandung: PT Remaja Rosda Karya, 2000.

Sukmadinata, Metode Penelitian Pendidikan, Bandung: Remaja Rosda Karya, 2009.

Suryabrata, Sumadi, Psikologi Pendidikan, Jakarta: Rineka Cipta, 2005.

Tampubolon, D.P. , Mengembangkan Minat Membaca Pada Anak, Bandung: Angkasa, 1998.

Thoha, Chabib, Pendidikan Islam, Yogyakarta, Pustaka Pelajar, 1996.

Tim Penyusun Kamus Pusat Bahasa, Kamus Besar Bahasa Indonesia, Edisi Ketiga, Departeman Pendidikan dan Kebudayaan, Jakarta: Balai Pustaka, 2001. 